\title{
Indexicality and Cognitive Significance: the Indispensability of Sense
}

\section{JOÃO BRANQUINHO*}

\begin{abstract}
This paper is devoted to the topic of indexicality in relation to the problem of cognitive significance. I undertake a critical examination of what I call the Millian Notational Variance Claim; this is the claim that those versions of a neo-Fregean semantics for demonstratives and other indexicals which rest upon the notion of a de re sense are eventually notational variants of a directly referential or Millian semantics for indexicals. I try to show that several lines of reasoning that might be pursued by Millian theorists with a view to establishing the Millian Notational Variance Claim are inconclusive, and hence that the claim is in general unsound. The problem of cognitive significance is tackled in connection with those categories of indexicals concerning which neo-Fregeanism and Millianism are alleged to yield similar results, viz. temporal indexicals, spatial indexicals, and perceptual demonstratives. I argue towards the conclusion that the notions the Millian theorist might invoke to accommodate the phenomena of cognitive significance in this area of indexicality are hardly adequate to the effect, and hence that senses are indispensable also here.
\end{abstract}

Keywords: cognitive value, direct reference, indexicals, propositional attitudes, sense.

\section{Notational Variance Arguments}

ne might summarize as follows the main sort of criticism developed
by Millian theorists. ${ }^{1}$ It is argued that neo-Fregean theories about
de re modes of presentation ${ }^{2}$ for indexical expressions are bound

* Universidade de Lisboa.

$\triangle$ jbranquinho@campus.ul.pt

1. Nathan Salmon, Frege's Puzzle (Cambridge, Mass. and London, England: The MIT Press, 1986). Nathan Salmon, "Illogical Belief", in Philosophical Perspectives, Vol. 3: Philosophy of Mind and Action Theory, ed. James E. Tomberlin (Atascadero: Ridgeview, 1989), 243-285. Nathan Salmon, "A Millian heir rejects the wages of Sinn", in Propositional Attitudes: The Role of Content in Logic, Language and Mind, ed. C.A. Anderson and J. Owens (Stanford: CSLI, 1990), 215-48. Scott Soames, "Direct Reference, Propositional Attitudes, and Semantic Content", Philosophical Topics 15 (1987): 47-87. Reprinted in Propositions and Attitudes, ed. Nathan Salmon and Scott Soames (Oxford: Oxford University Press, 1988), 197-239. Scott Soames, "Substitutivity", in On Being and Saying: Essays for Richard Cartwright, ed. J.J. Thomson (Cambridge: Cambridge University Press, 1988), 99-132. Scott Soames, "Review of Gareth Evans, Collected Papers", The Journal of Philosophy 86 (1989): 141-56.

2. Concerning the general notion of a de re sense, see John McDowell, "De Re senses", 
to face the following dilemma. Either they can be reconstructed as notational variants of direct reference theories, de re indexical senses having no clear explanatory function and being thus wholly dispensable in favour of a Millian semantics for indexicals; or they yield results which are unacceptable in the light of our intuitions about the use of indexicals in the ascription of attitudes. In what follows, I concentrate on the first horn of this putative dilemma, even though I also consider some issues related to the ${ }^{2}{ }^{3}$

Ine Millian theorist typically argues for the semantic redundancy of indexical modes of presentation by claiming that de re senses are not needed to explain apparent failures of substitutivity of co-referential indexicals in attitude-ascriptions, or to block certain apparently problematic results involving attitudes. ${ }^{4}$ If sound this claim would constitute a serious objection to any Fregean account of indexicality, since what is taken to be the privileged role of senses, and what is often proposed as the crucial rationale for their introduction, consists precisely in their status as theoretical entities postulated to explain why co-referential singular terms are not in general interchangeable salva veritate when occurring in the embedded sentences of propositional-attitude constructions. The antiFregean argument for the above claim runs as follows. Clearly, a necessary condition for inferences falling under the general pattern $\mathbf{x}$ V's that S(i), $\mathbf{i}=\mathbf{i}$. Ergo, $\mathbf{x}$ V's that $\mathbf{S}(\mathbf{i})(D)$ be rated as invalid by the proponent of a Fregean theory is that such a theory must provide us with a criterion for sameness of indexical sense; that is, it should state clearly under what conditions an indexical $\mathbf{i}$ used in a context $\mathbf{c}$ has the same sense as an indexical $\mathbf{i}^{\prime}$ used in a context $\mathbf{c}^{\prime}$. And, since sameness of reference is

The Philosophical Quarterly, volume 34, no. 136 (1974): 98-109. A criticism of the general notion is available in Stephen Schiffer, "The Mode-of-Presentation Problem", in Propositional Attitudes: The Role of Content in Logic, Language and Mind, ed. C.A. Anderson and J. Owens (Stanford: CSLI, 1990), 249-68.

3. The following papers critically deal with other (related) aspects of Millian notational variance arguments. João Branquinho, “Are Salmon’s 'Guises' Disguised Fregean Senses", Analysis 50 (1990): 19-24. João Branquinho, "On the persistence and re-expression of indexical belief", Manuscrito, volume 31, no. 2 (2008): 573-600. For a critique of the approach developed in the latter paper and for a different view, see Kurt C.M. Mertel, "Re-Thinking Gareth Evans' Approach to Indexical Sense and the Problem of Tracking Thoughts", Grazer Philosophische Studien, volume 94, Issue 1-2 (2017): 173-193.

4. Soames, "Review of Gareth Evans, Collected Papers", 154-5. Although Soames's arguments are mainly directed against Evans's particular version of Fregeanism, they could be easily generalized to other neo-Fregean approaches.

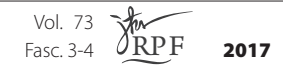


thought of as being necessary for sameness of sense, one should expect such a test to be given in particular for the case in which the referent of $\mathbf{i}$ in $\mathbf{c}$ is identical with the referent of $\mathbf{i}^{\prime}$ in $\mathbf{c}^{\prime}$. Yet, the Fregean theory does not contain a uniform criterion for the sameness of indexical sense, i.e. a means of decision capable of being applied to the different categories of indexicals, such as personal pronouns like 'I' and 'he', demonstratives like 'this' and 'that', temporal indexicals like 'now' and 'today', etc. Therefore, it is in general unclear how an appeal to senses might even account for failures of substitutivity (assuming for the sake of argument the antiMillian thesis that co-referential indexicals are not interchangeable salva veritate in attitude contexts). The Millian critic would discern a certain tension in the neo-Fregean account, a tension which reflects the alleged absence of a clear and uniform means of individuating indexical senses. On the one hand, the Fregean treatment of temporal indexicals, spatial indexicals, and perceptual demonstratives allows utterances of sentences containing different but co-referential indexicals of these kinds, as used in distinct contexts, to express the same (token) Fregean thought; hence, it allows the possibility of the same particular mode of presentation being associated with different indexicals in different contexts of use. As a result, substitutivity and other problematic results about attitude-ascriptions would apparently be forthcoming in a neo-Fregean account of such categories of indexicals. On the other hand, the Fregean treatment of personal pronouns precludes utterances of sentences containing distinct but co-referential indexicals (used in possibly different contexts) from expressing the same (token) Fregean thought; hence, it disallows the possibility of the same particular sense being attached to different indexicals of that sort (in possibly different contexts). As a result, substitutivity and other problematic results about attitude-ascriptions would be blocked in a neo-Fregean account of such a category of indexicals. The consequences the Millian theorist urges us to draw from the adoption of such allegedly disparate verdicts on sameness of indexical sense are as follows. If indexical expressions are treated along the lines suggested above for temporal indexicals, etc., then the resulting theory will no longer be Fregean in nature; it will be simply a notational variant of a direct reference theory, redundant de re indexical senses being eliminable and the referents of indexicals in given contexts doing all the relevant semantic work. If, on the other hand, indexicals are to be treated on the model of personal pronouns, then the resulting theory, though presumably Fregean in nature, will be implausible since some of its consequences are incompatible with the way we intuitively use indexicals in attitude-ascriptions.

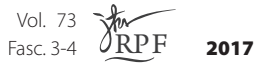


The implication is, of course, that we should generalize in the former direction, i.e. from temporal indexicals to other indexicals, in which case the Millian Notational Variance Claim would be warranted.

Before assessing the claim, let us check the details involved therein.

According to the brand of neo-Fregeanism put forward by philosophers like Gareth Evans, Christopher Peacocke and others, ${ }^{5}$ the following kind of result holds with respect to indexical expressions such as perceptual demonstratives and temporal and spatial indexicals. There are circumstances in which two (syntactically simple) indexicals $\mathbf{i}$ and i' of those types, taken as used in distinct contexts $\mathbf{c}$ and $\mathbf{c}^{\prime}$ where they turn out to be co-referential, are to be seen as expressing the same particular sense, or as being associated in $\mathbf{c}, \mathbf{c}^{\prime}$ with the same particular way of thinking of their common denotation. As a result, sentences $\mathbf{S}(\mathbf{i})$ and $\mathbf{S}\left(\mathbf{i}^{\prime}\right)$ uttered in c, $\mathbf{c}^{\prime}$ are assigned the same propositional content, i.e. the same Fregean thought, with respect to $\mathbf{c}, \mathbf{c}^{\prime}$.

Take the case of spatial indexicals. Suppose that on a certain occasion I am at a certain place $\mathbf{p}$, e.g. a certain corner of my living-room, and that I utter a token of the sentence

\section{(1) It is cold here.}

I then move to a different place $\mathbf{p}^{\prime}$, e.g. the opposite corner of my living-room, and utter a token of the sentence

5. Frege is "neo-Fregean" on this score. See Gottlob Frege, "The Thought: A Logical Inquiry", translated by Anthony and Marcelle Quinton, in Philosophical Logic, ed. Peter F. Strawson (Oxford: Oxford University Press, 1967), 17-38. See also the following articles defending neo-Fregeanism about indexicals. Gareth Evans, "Understanding Demonstratives", in Meaning and Understanding, ed. Herman Parret and Jacques Bouveresse (Berlin: W. de Gruyter, 1981). Reprinted in Gareth Evans, Collected Papers (Oxford: Clarendon Press, 1985), 291-321. Gareth Evans, The Varieties of Reference, ed. John McDowell (Oxford: Clarendon Press and New York: Oxford University Press, 1982), 291-321. Graeme Forbes, "Indexicals and Intensionality: A Fregean Perspective", The Philosophical Review volume 96, no. 1 (1987): 3-31. Graeme Forbes, "Indexicals", in Handbook of Philosophical Logic, Volume IV, ed. D. Gabbay and F. Guenthner (Dordrecht: David Reidel, 1989), 463-90. Christopher A.B. Peacocke, Sense and Content. Experience, Thought and their Relations (Oxford: Clarendon Press), 1983. Christopher A.B. Peacocke, Thoughts: An Essay on Content (Oxford: Basil Blackwell, 1986). For a more recent and rather sophisticated neo-Fregean approach, see François Récanati, Mental Files in Flux (Oxford: Oxford University Press, 2016), especially Chapter 6 .

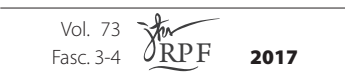




\section{(2) It is cold there}

(while pointing to $\mathbf{p}$ ). Then, on the neo-Fregean view, the co-referential indexicals 'here' and 'there' in (1) and (2) have the same sense with respect to the contexts in question: in both cases I am entertaining the same way of thinking of a place (viz. p); and with my utterances of (1) and (2) I am expressing the very same Fregean thought ${ }^{6}$.

Or take the case of perceptual demonstratives. Suppose that I am faced with a set of briefcases. I hold one of them and assert

\section{(3) This briefcase is heavy.}

A few moments later, having managed in some way to track the briefcase in question, I point at it from a distance and assert

\section{(4) That briefcase is heavy.}

Again, according to the neo-Fregean account, I attach to the demonstratives 'this' and 'that' in (3) and (4) the same mode of presentation of an object; in spite of there being superficial differences between the tactual way of thinking of it I employ in (3) and the visual way of thinking of it I employ in (4), I am expressing the same particular Fregean thought on both occasions.

Now a familiar anti-Fregean notational variance claim is that there would be no substantive way by means of which one would be able to distinguish the above sort of account from a direct reference theory of indexicals. It is alleged that results which are quite similar to the ones outlined are forthcoming in such a theory, and that the differences between the two kinds of account might be counted as being minor (simply terminological) ones. In effect, given the same set of starting assumptions about indexicals $\mathbf{i}$ and $\mathbf{i}^{\prime}$ in contexts $\mathbf{c}$ and $\mathbf{c}^{\prime}$, and given that (syntactically simple) indexicals are construed as directly referential expressions, it follows that $\mathbf{i}$ and $\mathbf{i}$ ' in c, c' make exactly the same contribution to propositional content; indeed, on the Millian view, they just contribute their common denotation with respect to the given contexts $\mathbf{c}, \mathbf{c}^{\prime}$. Hence, assuming compositionality, the propositions expressed by sentences $\mathbf{S}(\mathbf{i})$ and $\mathbf{S}\left(\mathbf{i}^{\prime}\right)$ in $\mathbf{c}, \mathbf{c}^{\prime}$ are one and the same, viz. a certain neo-Russellian proposition. Thus, in our examples, the tokens of 'here' and 'there' in (1) and (2) (respectively the tokens of 'this' and

6. I ignore the difference in time of 'it is'.

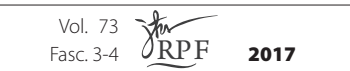

Provided for Personal License use. Not for reproduction, distribution, or commercial use. () 2017 Revista Portuguesa de Filosofia. All Rights Reserved. 
'that' in (3) and (4)) make the same contribution to propositional content with respect to the contexts in question: they contribute $\mathbf{p}$ (respectively the briefcase referred to); and with my utterances of (1) and (2) (respectively (3) and (4)) I am expressing the same proposition, viz. the ordered pair of $\mathbf{p}$ and Coldness (respectively the ordered pair of the briefcase and the property of being heavy).

\section{Against Notational Variance}

Before dealing with the Millian arguments about attitude-ascriptions involving indexicals (see Section 3), let us consider the Millian criticism that, therefore, it looks as if on the neo-Fregean view it is the identity of the referents of the indexicals $\mathbf{i}, \mathbf{i}^{\prime}$ in $\mathbf{c}$, $\mathbf{c}^{\prime}$ which is actually determining the identity of the singular senses they allegedly express in these contexts; and that it seems that it is the de re nature attributed to such senses which makes them entirely dependent upon the objects they present, these doing all the relevant semantic job.

I think that such a criticism is unwarranted. Briefly stated, my main objection is that it involves the following sort of non sequitur. From the supposition that indexicals $\mathbf{i}$ and $\mathbf{i}$ (of the envisaged types) - taken as referring to the same object, say $\mathbf{o}$, in contexts $\mathbf{c}$ and $\mathbf{c}^{\prime}$ - may be assigned the same singular sense in $\mathbf{c}$, $\mathbf{c}^{\prime}$ it does not follow that it is the identity of their common denotation o which determines their senses as being identical in c, c'; surely, a different sort of consideration might be used by the neo-Fregean theorist, and is actually used (see below), to argue for such a sameness of sense. Although there is a sense in which, in general, a de re mode of presentation $\mathbf{m}$ of an object $\mathbf{o}$ depends upon the very existence of $\mathbf{o}$, viz. the sense in which $\mathbf{m}$ would not be available to be employed if $\mathbf{o}$ did not exist, this does not by itself allow us to say that the indexical modes of presentation attached to $\mathbf{i}, \mathbf{i}^{\prime}$ in $\mathbf{c}, \mathbf{c}^{\prime}$ are identical because they are both ways of thinking of the same object $\mathbf{o .}$

Indeed, consider Evans's account of indexical reference, for instance. Evans establishes certain results about identity of sense between co-referential indexicals $\mathbf{i}, \mathbf{i}^{\prime}$ in contexts $\mathbf{c}, \mathbf{c}^{\prime}$, not from considerations about identity of reference (though this is surely a necessary condition for sameness of sense), but from considerations arising out of a substantive elucidation of the notion of an indexical way of thinking of an object. Roughly stated,

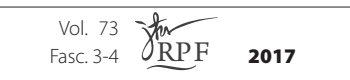


Evans's proposal ${ }^{7}$ consists in explaining this notion in terms of the notion of an account of the conditions under which a subject's indexical thought is about the object it is about; and this involves in turn giving an account of how the subject knows which object is in question. Thus, in certain cases the sense of $\mathbf{i}$ in $\mathbf{c}$ is the same as the sense of $\mathbf{i}^{\prime}$ in $\mathbf{c}^{\prime}$ because the account of the conditions under which the subject's indexical thought in $\mathbf{c}$ is about $\mathbf{o}$ is taken to be the same as the account of the conditions under which the subject's thought in ' $\mathbf{c}^{\prime}$ is about o. And, in general, this is so when the subject is in the same epistemic state in $\mathbf{c}$ and $\mathbf{c}^{\prime}$, i.e. when she exercises in $\mathbf{c}$ and $\mathbf{c}^{\prime}$ the same ability to think of the object $\mathbf{o}$. In the case of temporal indexicals such as 'today' and 'yesterday' - as employed e.g. in (5) and (6) below - the ability in question will be the ability to keep track of a time (a day) as time passes by. In the case of spatial indexicals such as 'here' and 'there' - as employed e.g. in (1) and (2) - it will be the ability to keep track of a place as one moves about. And in the case of perceptual demonstratives such as 'this' and 'that' - as employed e.g. in (3) and (4) - it will be the ability to keep track of a spatio-temporal particular from sensory modality (e.g. touch) to sensory modality (e.g. sight).

Thus, on such a view, indexical modes of presentation are individuated, not (or, better, not only) in terms of the identity of the particular objects referred to in given contexts, but in terms of certain ways of keeping track of such objects a thinker may employ. Of course, none of the above abilities could be exercised by a thinker in the absence of a particular object to which the thinker stands in a certain suitable (possibly causal) relation. But this is tantamount to saying that the indexical and demonstrative senses grounded on such abilities are de re in nature; it surely does not mean that the presented Res is doing all the job involved in the individuation of indexical content. I conclude that there seems to be no sense in which neo-Fregean accounts of the kind discussed might be construed as implicitly arguing from sameness of indexical reference to sameness of indexical sense, and hence to sameness of indexical content (with respect to those cases where sameness of indexical content is indeed acknowledged by the neo-Fregean theorist, e.g. cases like (1) and (2) or (3) and (4) taken in the envisaged contexts of use).

7. Evans, “Understanding Demonstratives”, 294, 303. Evans's ways of thinking of objects are governed by what he calls Russell's Principle: in order to make a judgement about an object one must know which object is in question. See also Evans, The Varieties of Reference, 65.

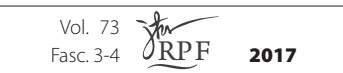


Furthermore, it may be conclusively shown that the impression of similarity between the Millian account and the neo-Fregean one is nothing but deceptive (relative to the sort of semantic treatment given to utterances containing indexicals of the kinds under consideration). In effect, whereas the former kind of account invariably yields the result that indexicals $\mathbf{i}$ and i', used in contexts $\mathbf{c}$ and $\mathbf{c}^{\prime}$ where they are co-referential, have the same semantic content with respect to $\mathbf{c}, \mathbf{c}^{\prime}$, the same cannot be said of the latter kind of account. The reason is that the neo-Fregean approach makes room for the existence of a certain range of cases concerning which one obtains precisely the opposite sort of result; in such cases indexicals $\mathbf{i}$ and $\mathbf{i}$ ' which are co-referential in contexts $\mathbf{c}$, $\mathbf{c}^{\prime}$ are assigned different Fregean senses, and hence different semantic contents with respect to $\mathbf{c}, \mathbf{c}^{\prime}$.

To appreciate this, consider the following situation involving spatial indexicals. Suppose that I am at a certain place $\mathbf{p}$ in the middle of a desert and I assert 'It is hot here'. Suddenly there is a sand storm, I get lost and it happens that (unbeknownst to me) I am driven to the same place, viz. p. Suppose that then I assert again 'It is hot here'. On the Millian view, the distinct tokens of 'here' I use on those occasions are presumably assigned the same propositional value, viz. p, and my utterances are presumably assigned the same semantic content (modulo a difference in the times of the utterances, which I ignore for the present purposes). Yet, on the neo-Fregean view, given the proposed individuation of indexical senses in terms of keeping track of things, the result is not forthcoming that I entertain the same way of thinking of a place on both occasions, or that I attach to the distinct tokens of 'here' the same sense. Indeed, on such a view, either I am described as attaching no sense at all to the token of 'here' I use on the latter occasion, and hence as not really expressing then any proposition at all; or I am described as entertaining a different sense, and hence as expressing a different proposition. At any rate, it is not the case that the tokens of 'here' I employ have the same propositional value with respect to the contexts in question, though they are certainly co-referential in such contexts (if they have senses at all).

And the above case has the following sort of temporal analogue. Suppose that on a certain day d, during the afternoon, someone (say John) assertively utters the sentence 


\section{(5) Today is fine,}

and I agree with him. Then I take a nap, a "nap" which in fact lasts for 24 hours. When I wake up in the afternoon of $\mathbf{d}+\mathbf{1}$, wrongly thinking that I have slept for a short period, I hear John assertively uttering the sentence

\section{(6) Yesterday was fine;}

and I also agree to this (on the basis of what the weather was like on d-1). Suppose further that, unlike me, John has correctly kept track of the days from $\mathbf{d}$ to $\mathbf{d + 1}$. On the Millian view, with his utterances of (D) and $(2)$ in the above contexts, the speaker (John) expresses and belleves the same neo-Russellian proposition at different times (though under different characters). As to the hearer (myself), such a view would probably describe him as unknowingly entertaining and believing the same neo-Russellian proposition at different times (under different characters as well).

I take such a sort of description as intuitively implausible, this being a consequence of the general semantic insensitivity to the cognitive aspects of language use displayed by Millian accounts; but that is irrelevant for my immediate concerns. What really matters is that there is a conspicuous dissimilarity between the above account and the way a neo-Fregean theory would treat the same sort of case. On this view, speaker and hearer would be described as diverging with respect to the indexical contents they associate with (5) and (6) in the contexts in question. As already noted, John would be regarded as attaching the same particular sense to the given tokens of 'today' and 'yesterday', or as thinking of $\mathbf{d}$ in the same way on both occasions, and hence as expressing and believing the same Fregean thought at different times. Yet, I would be in no position to grasp, and thus to believe, that Fregean thought, at least as it is expressed by John when he utters (6) on $\mathbf{d + 1}$. In effect, according to such a form of neo-Fregeanism, I attach to John's use of 'yesterday' in (6) a sense which is different from the one he employs, and then (given the circumstances) I am unable to entertain this sense; or, more likely, I do not attach any sense to it at all - I am only under the illusion that I am then employing a way of thinking about a particular day - and thus I am actually unable to grasp the Fregean thought expressed by John on $\mathbf{d}+\mathbf{1}$.

As a parenthetical remark, it should be noticed at this point that I am not necessarily endorsing the particular neo-Fregean account of temporal indexicals we have been discussing; maybe results of the above sort are also in a sense contrary to our intuitions. Our current focus on such a view

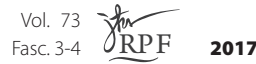


is mainly due to the fact that it is the sort of neo-Fregean view to which the Millian notational variance arguments are par excellence applicable. But there are other possible neo-Fregean accounts of temporal indexicality which would be from the outset immune to such arguments. For instance, one might hold the view ${ }^{8}$ that there are no circumstances under which any given tokens of 'today' and 'yesterday' might be assigned the same Fregean sense, even in contexts in which they have the same reference and in which the speaker does not mistrack time. And such a view, which in the above respects departs significantly from Frege's original doctrine, might still preserve the principle that indexical sense is not constant across contexts; in the sense that e.g. tokens of 'today' uttered on different days necessarily express different particular senses, though they might be assigned the same type of sense. That principle is in fact an instance of the general Fregean principle that sense determines reference, construed as the claim that the sort of correspondence obtaining between reference and senses is necessarily one-to-many ${ }^{9}$. Thus, one could take the sense of a token of 'today' - uttered on a certain occasion - as being that of the (impure) description 'the day of this utterance', where the demonstrative refers to that very utterance of 'today'. Likewise, one could take the sense of a particular token of 'yesterday' - uttered on a certain occasion - as being that of the description 'the day immediately before the day of this utterance', where the demonstrative refers to that very utterance of 'yesterday'. This would not necessarily force us to regard the description giving the sense of each temporal indexical as providing us with a definition of the indexical in question, i.e. as being analytically equivalent to it. Indeed, on the one hand, the proposition expressed e.g. by an utterance on a particular day $\mathbf{d}$ of the sentence

\section{(7) Today is the day of this utterance}

(where 'this utterance' is self-referential), seems to be $a$ priori with respect to a fully competent speaker of English (the negation of (7) would be epistemically impossible for her). Yet, on the other hand, such a proposition

8. This is the sort of view adopted by Searle. See John Searle, Intentionality: An Essay in the Philosophy of Mind (Cambridge: Cambridge University Press, 1983), 218-30.

9. Such a principle is explicitly rejected in the account of indexical modes of presentation developed in Colin McGinn, The Subjective View (Oxford: Clarendon Press, 1983), Chapter 5. On such an account, indexical senses - such as those associated with 'today' or ' $\mathrm{I}$ ' - are constant across contexts: they always present their (possibly different) referents in the same way.

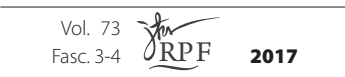


should be regarded, not as (metaphysically) necessary, but as contingent; for the day $\mathbf{d}$ might exist without any utterance of (7) having been made on $\mathbf{d}$, in which case the proposition expressed by 'Today might not have been the day of this utterance' would be counted as true.

If the above suggestion were along the right lines then one should regard tokens of 'today' and 'yesterday' used in contexts where they have the same reference (e.g. (5) and (6) as uttered by John) as containing different modes of presentation of the same day, and hence the Fregean thoughts expressed in such contexts could not be one and the same. And such a difference in sense might be seen as a difference in the conceptual ingredients making up the descriptions associated with the indexicals (assuming that sense is, in general, what is expressed); 'yesterday' would thus be conceptually dependent upon 'today', since its associated description contains the sense of 'today' as a component part. ${ }^{10}$

\section{Indexical Sense and Attitude-reports}

I turn now to the Millian arguments concerning attitude-attributions. Recall that one of the claims here is that neo-Fregeanism of the sort described earlier on would entail the prima facie unFregean consequence that certain transitions (see below) between attitude-reports containing occurrences of co-referential indexicals (of the envisaged kinds) within the 'that'-clauses are to be rated as legitimate; thus, in this respect there would be again no difference between such a Fregean theory and a Millian one, from which the consequence in question is in general acknowledged to be derivable. And a different (but related) kind of claim is that the neo-Fregean would apparently put a Fregean believer in the same sort of position as Salmon's Millian believer Elmer, ${ }^{11}$ who believes - at a given time or, without changing his mind, on different occasions - a pair of mutually inconsistent propositions while failing to recognize the same proposition in both cases and hence without being illogical; thus, likewise, there would allegedly be Fregean thoughts which are not completely transparent to their thinkers.

10. The sort of account just outlined could perhaps be generalized to other temporal indexicals, such as e.g. 'tomorrow' and 'now'; but I doubt that it could be also plausibly applied to spatial indexicals or perceptual demonstratives.

11. Salmon, Frege's Puzzle, $92 \mathrm{ff}$.

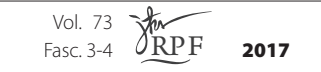


Let us once more focus on temporal indexicals (having in mind that the results obtained might easily be made to apply to spatial indexicals and perceptual demonstratives). Suppose that Jones, a logical thinker and a fully competent speaker of English, sincerely and reflectively assents at a certain time $\mathbf{t}$ on a certain day $\mathbf{d}$ to a token of the sentence-type (5). Accordingly, one would expect the belief-ascription

\section{(8) Jones believes that today is fine,}

as uttered by someone (say Ralph) at a certain time $\mathbf{t}^{\prime}$ on $\mathbf{d}$, to be true of Jones (here $\mathbf{t}^{\prime}>\mathbf{o r}=\mathbf{t}$, and if $\mathbf{t}^{\prime}>\mathbf{t}$ one would have also to suppose that Jones does not change his mind about the weather on $\mathbf{d}$ at any time between $\mathbf{t}$ and $\mathbf{t}^{\prime}$ ). Now the sort of neo-Fregean account subscribed to e.g. by Evans would entail, given certain additional assumptions, the consequence that the belief-report

\section{(9) Jones believes that yesterday was fine,}

as uttered by Ralph at a certain time $\mathbf{t}$ " on $\mathbf{d + 1}$, is also true of Jones. And the assumptions in question are: (i) - that Jones keeps track of the days from $\mathbf{d}$ to $\mathbf{d}+\mathbf{1}$ (and one would have also to assume that the ascriber, i.e. Ralph, does not mistrack time either, otherwise there might be a possible divergence between the senses attached by him and by Jones to 'yesterday'); and (ii) - that on $\mathbf{d + 1}$ Jones has not changed his beliefs about the weather on $\mathbf{d}$.

Therefore, it seems that the neo-Fregean theory validates transitions such as the one from (8) to (9). In general, such transitions might be characterized as consisting in carrying out the following two steps: (i) - interchanging certain pairs of co-referential indexicals within the (semantic) scope of psychological verbs in propositional-attitude constructions, e.g. replacing in (8) 'today' by 'yesterday'; and (ii) - readjusting in an appropriate way the times at which the attitudes are held, e.g. changing the time t' (or the day d) of Jones's belief in (3) to t" (or to $\mathbf{d + 1}$ ). As already noticed, in virtue of step (ii), the transitions m question are obviously not cases of substitutivity salva veritate; thus, there is a clear contrast between moves of the above sort and moves such as e.g. the one from ' $I$ believe at $\mathbf{t}$ that I am ugly' to 'I believe at that he is ugly', which, assuming that I am the male demonstrated at $\mathbf{t}$, is a valid move according to a Millian theory of indexical belief (but an invalid one on a Fregean view).

vol. 73
Fasc. 3-4 $\underset{\text { RPF }}{\mathbf{R}} \mathbf{2 0 1 7}$


However, contrary to the Millian claim, the sort of consideration employed by the neo-Fregean theorist to ensure the legitimacy of a transition such as the one from (8) to (9) (under the given circumstances) has nothing to do with a mere identity of indexical reference. Indeed, according to his proposed individuation of temporal modes of presentation in terms of ways of tracking times, the neo-Fregean theorist is appealing rather to identity of indexical sense here. The sense referred to by 'today' in (8) is judged to be the same as the sense referred to by 'yesterday' in (9), the same particular way of keeping track of a day (viz. d) being employed by Jones on both occasions. Hence, denoting such a common mode of presentation of $\mathbf{d}$ by ' $\mathbf{M P} \mathbf{P}_{\mathbf{d}}$ ', the belief-reports (8) and (9) might be (respectively) given, with respect to the contexts in question, the following sort of representations under the envisaged neo-Fregean account:

\section{(8)' $\mathrm{B}_{\mathrm{t}^{\prime}}\left[\right.$ Jones, $<\mathrm{MP}_{\mathrm{d}}$, Fineness $\left.>\right]$}

\section{(9)' $\mathbf{B}_{\mathrm{t}^{\text {"}}}$ [Jones, $<\mathrm{MP}_{\mathrm{d}}$, Fineness $>$ ]}

(the Fregean thoughts believed by Jones at different times being thus one and the same); here ' $\mathbf{B}_{\mathbf{t}}$ ' stands for the binary Belief-relation as relativized to a certain time $\mathbf{t .}^{12}$

I want now to argue with a view to establishing the following two points, which taken together provide us with a refutation of the Millian arguments for the dispensability of de re indexical senses. First, on the above sort of neo-Fregean view, it turns out that transitions of the form mentioned earlier on may fail to obtain; and such a possibility, which is presumably unavailable under a Millian account, is also explained by means of an appeal to indexical senses. Secondly, contrary to appearances, the Millian critic is definitely wrong when he holds that in the end one would not be able to differentiate between Fregean thinkers and Millian thinkers in respect to the possibility of unknowingly believing contradictory thoughts. The upshot of my discussion is that the main rationale for the introduction of senses in a semantic theory, viz. that of blocking problematic results involving attitudes, is still available in this area of indexicality.

12. I employ the usual notation of ordered pairs only for reasons of simplicity; in fact, it sounds strange to say that believing a Fregean thought is something like standing in a certain relation to a set.

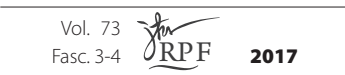


As to the first point, it is indeed a feature of the neo-Fregean account, a feature which is not usually displayed by a Millian semantics for e.g. ascriptions of temporal beliefs, that transitions sharing the form of the one from (8) to (9) are not always legitimate under it; i.e., there are circumstances in which, although such an account would count a token of a sentence sharing the form of (8) (used on $\mathbf{d}$ ) as holding, it would not count a token of a sentence sharing the form of (9) (used on $\mathbf{d + 1}$ ) as holding at all. In effect, consider the case (introduced before) in which, after assenting on $\mathbf{d}$ to a token of (5) uttered by John, I take a 24-hour "nap" and unknowingly lose track of the days. Thus, John's belief-ascription on d

\section{(10) He believes that today is fine}

(where 'he' refers to me) would be true. Yet, my assenting on $\mathbf{d}+\mathbf{1}$ to a token of (6) uttered by John does not put him in a position to make on $\mathbf{d + 1}$ the following belief-ascription:

\section{(11) He believes that yesterday was fine.}

Assume that John reports all his beliefs according to the neo-Fregean theory, that he keeps track of the days correctly, that he remembers the weather on the previous day, and that he is aware of my situation. Then, since when I give my assent to (6) I am not actually entertaining any way of thinking of $\mathbf{d}$, I am not entertaining then any Fregean thought about $\mathbf{d}$, and hence I am not having any belief whatsoever about $\mathbf{d} .{ }^{13}$ Therefore, (11) does not come out as true under the neo-Fregean account (with respect to the given context), but rather as a false belief-ascription. Hence, the following report

\section{(12) He lacks the belief that yesterday was fine}

(as uttered by John on $\mathbf{d + 1}$ ) would come out as true (assuming that (12) is the negation of (11)). ${ }^{14}$

13. Here one would have to rule out the possibility that (11) is true because of some mode of presentation of $\mathbf{d}$ under which I have the belief and which I do not associate with the word 'yesterday', e.g. a memory-based mode of presentation of $\mathbf{d}$.

14. Note that in place of (12) one might have used

(13) He does not believe that yesterday was fine

(which is - at least syntactically - a straightforward negation of (11)). The problem with a report such as (13) - and the reason why I avoid employing it - is that it is am-

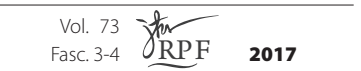


Obviously, this kind of result would not constitute any problem for neo-Fregeanism since the thought expressed by (12) would not be inconsistent with the one expressed by (10); and hence the ascriber (John) would not be contradicting himself, the Fregean regimentations for such belief-reports being:

\section{(10)' $\quad$ B $_{d}\left[\right.$ J.B., $<$ MP $_{d}$, Fineness $\left.>\right]$ \\ (12)' $\neg B_{d+1}\left[\right.$ J.B., $<M_{d}$, Fineness $>$ ].}

At most, the neo-Fregean account would allow a thinker to hold at different times conflicting attitudes towards the same proposition.

From the preceding reflection I think that one is entitled to draw the conclusion that, from the standpoint of the neo-Fregean account of indexicality, there are in fact illegitimate transitions involving co-referential indexicals of the envisaged types in attitude-ascriptions, and that it is in terms of indexical Sinne that such an illegitimacy is to be accounted for.

It could be replied that there is a sense in which the transitions in question might also be deemed illegitimate on a Millian view. Suppose that one supplements a directly referential account of temporal indexicals, spatial indexicals and perceptual demonstratives with some epistemic notion of tracking an object over time and/or space. And suppose that it is possible to do it in such a way that the following sort of general condition would obtain: there exists a guise (or other suitable Millian construction) under which a given subject stands in the Belief-relation to a neo-Russellian proposition containing an indexically presented time, or place, or spatio-temporal item, only if the subject is somehow able to track the time, or the place, or the spatio-temporal item, in question. Then Millianism could presumably be made to yield the same verdicts as neo-Fregeanism on the truth-values of certain belief-ascriptions containing indexicals of the above kinds. For instance, reports like (10) and (12) would both come

biguous between (12) and

(14) He disbelieves that yesterday was fine,

or

(15) He believes that yesterday was not fine

(which I construe as having the same meaning as (14)). If (13) were read in the sense of (14) (or of (15)), then it would surely come out as false with respect to the case discussed; thus, a confusion between (13) and (14) (or (15)) would help generate the wrong conclusion that (13) is false and hence that (11) is true in our story (by means of the wrong premise that (13) - assimilated to (14) (or to (15)) - is the negation of (11)).

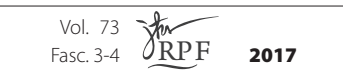


out as true, and (11) as false, under the extended Millian account (relative to the given contexts); so there are after all moves of the sort discussed which would not be validated by Millianism either. However, assuming that such a notion of tracking could be harmoniously incorporated into a Millian theory, it is obvious that it would have to be located at the pre-semantic level. As a result, the Millian and neo-Fregean analyses of belief-ascriptions of that kind, in spite of being materially equivalent, would not be logically equivalent to each other; a report like (12), for example, would be in each case assigned substantially different truth-conditions and meanings. And this would provide us with sufficient grounds on which to reject the Millian claim about notational variance. On the other hand, if a notion of tracking is to be in the end acknowledged as theoretically relevant, then one might always raise the question concerning the overall advantages, for explanatory purposes, of taking it as semantically relevant as well. Furthermore, cases might be introduced where the same object is tracked separately by hand and eye by a given subject and where she does not know that the touched object is the seen object. Concerning such cases, it is very likely that even the extended Millian account would yield different verdicts as the neo-Fregean account on the truth-values of belief-reports such as e.g. 'She believes that that (the touched object) is F' and 'She believes that that (the seen object) is $\mathbf{F}$ '.

As to the issue about the possibility of a (rational) subject's believing contradictory Fregean thoughts, consider the following sort of case. ${ }^{15}$ Suppose now that Jones sincerely and reflectively assents to a token of (5) on $\mathbf{d}$ at 11:58 p.m., so that (8) is then true of him; and that, without taking the trouble to look at his watch, three minutes later (i.e. at 00:01 a.m. on d+1) he sincerely and reflectively dissents from a token of (6) (thinking, of course, that he is referring to d-1). Assume further that the ascriber is as before, i.e. that he does not mistrack time, that he is aware of Jones's situation, etc. And one might also assume that, on the later occasion, Jones has not changed his mind about his previous belief (he remembers what the weather was like on d).

The question I want to take up, and to which I shall eventually give a negative answer, is this. Does it follow that the ascription

15. This happens to be the kind of case used by Soames in support of his notational variance arguments against neo-Fregeanism; see Soames, "Review of Gareth Evans, Collected Papers", 154-5.

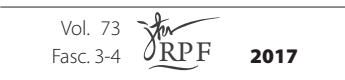




\section{(18)}

\section{Jones believes that yesterday was not fine,}

taken as uttered on $\mathbf{d + 1}$, holds of Jones? If so then a consequence of the neo-Fregean account would be that Jones, ex hypothesi a rational thinker, comes to believe a pair of contradictory thoughts on different occasions without apparently having meanwhile changed his mind (I think it would be manifestly implausible to construe (18) as implying that a change of mind has taken place). In effect, the thoughts referred to by the 'that'clauses in (8) and (18) would clearly contradict each other, the regimentations for (8) and (18) being:

\section{(8)" $\quad$ B $_{11: 58 \text { p.m.,d }}\left[\right.$ Jones, $<$ MP $_{d}$, Fineness $\left.>\right]$ \\ (18)' $\quad \mathbf{B}_{\text {00:01 a.m.,d+1 }}\left[\text { Jones, }<\text { MP }_{d} \text {, } 7 \text { Fineness }>\right]^{16}$}

A positive answer to the above question would thus give us the result that neo-Fregeanism is committed to reporting Jones's doxastic states in a way which is strikingly similar to the way in which a Millian theorist would report them. And an additional problem for neo-Fregeanism would be that it does not seem to contain a notion designed to fulfil a role similar to that of the Millian notion of a guise or appearance under which one may be acquainted with a proposition (such a role being mainly that of rendering given propositions opaque to the thinker's awareness, so that in some cases one may be prevented from re-identifying a proposition previously entertained). Take Salmon's Millian believers, for instance. They may find themselves in a situation in which they believe inconsistent propositions, at the same or at different times, but (if rational) they would necessarily do it under different guises; thus, Salmon's analyses for (8) and (18) (taken with respect to the given contexts) would be as follows:

\section{(8)"' $\quad(\exists g)\left[G_{11: 58 \mathrm{pm}, \mathrm{d}}\left(\right.\right.$ Jones, w,g) \& BEL $\mathbf{B L}_{1158 \mathrm{pm}, \mathrm{d}}($ Jones, w,g) $]$}

\section{(18)” ( $\exists h)\left[G_{00: 01 a m, d+1}(J o n e s, w, h) \& B E L_{00: 01 a m, d+1}(J o n e s, \neg W, h)\right]$}

(where 'w' stands for the Russellian proposition <d, Fineness $>$ and the guises $\mathbf{g}$ and $\mathbf{h}$ are obviously such that $\neg(\mathbf{g}=\mathbf{h}))$. On the other hand,

16. It is assumed that the negation of a thought consisting of a certain mode of presentation of an object and a property is the thought consisting of that mode of presentation and the negation of that property.

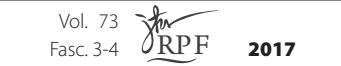


Fregean believers - who allegedly may also find themselves in a situation in which they believe contradictory thoughts (at different times) - do not seem to be credited with any sort of psychological device by means of which given thoughts could be concealed from them (so as to speak); modes of presentation will not do for on a Fregean view they are taken as constituent parts of thoughts. Indeed, unlike neo-Russellian propositions, Fregean thoughts are seemingly supposed to be completely transparent to their thinkers. Hence, the Millian critic might claim that Fregean believers have the disadvantage of being prevented from not recogn (2) gh that is one and the same proposition which is believed and disberreved by them on different occasions (Jones's putative situation when he assents to (5) and later on dissents from (6)).

However, such a move is doubtful. For its supporting premise, viz. the claim that neo-Fregeanism entails the problematic result under consideration, can be shown to be false. Indeed, given that Fregean indexical thoughts of the envisaged types are (partially) individuated in terms of abilities to track the objects thought about, a belief-report such as (18) taken as made on $\mathbf{d}+\mathbf{1}$ - would have to be counted as false (with respect to Jones's story); whereas, as assumed, ascription (8) - taken as uttered on d - holds of Jones. Thus, supposing that this sort of result may be extended to spatial indexicals and perceptual demonstratives, whose senses in given contexts are individuated along the same lines, the consequence is not in general derivable from the neo-Fregean account that it is possible for a subject (unknowingly) to believe, on different occasions but without having meanwhile changed her mind, mutually inconsistent thoughts.

If ascription (18) is false under neo-Fregeanism, then the following report

Jones lacks the belief that yesterday was not fine,

taken as made on $\mathbf{d + 1}$ at 00:01 a.m., will come out as true under such an account (with respect to Jones's story). Thus, using

$$
\neg B_{\text {00:01 a.m.,d+1 }}\left[\text { Jones, }<\text { MP }_{d} \text {, } \neg \text { Fineness }>\right]
$$

(i.e. the negation of (18)') as the Fregean regimentation for (19), and (8)" as the Fregean regimentation for (8), one might describe in general Jones's doxastic states by saying that on a certain occasion he believes a certain thought and on a later occasion he fails to believe the negation of that thought. Hence, the sort of case under discussion is definitely not a

vol. 73
Fasc. 3-4 每


case in which someone holds at different times antagonistic attitudes, e.g. belief and disbelief, towards the same thought.

A different way of establishing with respect to Jones's case the falsity of (18), and hence the truth of (D), might be given as follows. I take it that, according to neo-Fregeanism, the following result is true of Jones at 00:01 a.m. on $\mathbf{d + 1}$ :

(19)” $\neg(\exists \alpha)\left[T_{00: 01 \mathrm{am}, \mathrm{d}+1}(\right.$ Jones,d, $\alpha) \& \mathrm{~B}_{00: 01 \mathrm{am}, \mathrm{d}+1}[$ Jones, $<\alpha, \neg$ Fineness $\left.>]\right]$;

here ' $\boldsymbol{\alpha}$ ' ranges over temporal modes of presentation based on abilities to track days over time, and ' $\mathbf{T}$ ' stands for that relation which holds, at a given time, between a subject $\mathbf{x}$, an object $\mathbf{o}$, and a singular mode of presentation $\boldsymbol{\beta}$ if and only if, at that time, $\mathbf{x}$ thinks of $\mathbf{o}$ under $\boldsymbol{\beta}$. On the other hand, I also take it that such a theory rates as being in general valid inferences from given de dicto belief-ascriptions to the corresponding de re ones; that is, propositions of the general form

$$
\mathbf{B}_{\mathrm{t}}\left[\mathrm{x},<\mathrm{MP}_{\mathrm{o}}, \Phi>\right] \text {, }
$$

where 'MP.' and ' $\boldsymbol{\Phi}$ ' stand for a mode of presentation of an object $\mathbf{o}$ and a property (respectively), entail propositions of the form

\section{$(* *) \quad(\exists \beta)\left[T_{t}(x, o, \beta) \& B_{t}[x,<\beta, \Phi>]\right]$.}

(For convenience, I have only considered the case of beliefs in thoughts of the simplest predicative form.) Now the proposition which is the scope of the negation symbol in (19)" clearly displays the general form $(* *)$. Hence, since ex hypothesi (19)" is true in Jones's story, it follows that that proposition is false in his story. Therefore, the corresponding proposition of the form (*), which turns out to be (18)', is necessarily false in Jones's story. But (18)' is the Fregean regimentation for belief-ascription (18). Therefore, (18) comes out as false with respect to Jones's story.

It is instructive to compare the above neo-Fregean results with the results a Millian theorist dealing with the same sort of case would usually obtain. Thus, under Salmon's account, a belief-report such as (18) would turn out to be true with respect to Jones's story; for its Millian regimentation is given in (18)" and this proposition holds with respect to Jones's case (just let ' $\mathrm{g}$ ' in (18)" be 'Yesterday was fine'). Yet, Salmon's theory would rule out a belief-report such as (19) as false with respect to Jones's story. Indeed, the Millian regimentation for (19) would be given in

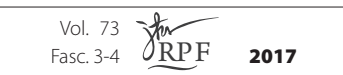


(19)”' ᄀ ( $\exists h)\left[G_{00: 01 a m, d+1}(J o n e s, w, h) \& B E L_{00: 01 a m, d+1}(J o n e s, \neg W, h)\right]$

(where ' $\mathbf{w}$ ' is to be read as before); and (19)'" is simply the negation of (18)". It should be apparent by now that the verdicts standardly given by the Millian theorist on the truth-values of attitude-ascriptions such as (18) and (19) taken in the envisaged contexts, respectively true and false, are strictly inconsistent with the verdicts given on them by the Fregean theorist, respectively false and true. Again, this would be enough to rebut the Millian Notational Variance Claim as applied to temporal and spatial indexicals and perceptual demonstratives. On the other hand, such a claim would be unsound even if the Millian theorist were to be credited with a pre-semantic notion of tracking in the way sketched earlier on: presumably, one would have the same assignments of truth-values; but one would not have the same assignments of truth-conditions.

\section{The Transparency of Indexical Sense}

Concerning the principle that Fregean thoughts are necessarily transparent to their thinkers, ${ }^{17}$ it is clear that such a principle is not threatened by the Millian arguments and that it is consistent with the preceding sort of Fregean results (though one might perhaps have independent reasons for rejecting it, even from a Fregean standpoint). Indeed, the relevant form of the Transparency principle might be given as follows:

\section{(T) If a rational subject $x$ believes that $p$ at $t$ and disbelieves that $q$ at $t^{\prime}$ and the thought that $p=$ the thought that $q$, then $x$ knows at $t^{\prime}$ that the thought that $p=$ the thought that $q\left(\right.$ with $t^{\prime}>$ or $\left.=t\right)$.}

Now if $\mathbf{t}^{\prime}=\mathbf{t}$ then a Fregean theorist would take (T) as being a trivially true claim for its antecedent should have to be counted as false: it is simply inconsistent with the Intuitive Criterion of Difference for thoughts. On the other hand, if $\mathbf{t}^{\prime}>\mathbf{t}$ - and this is the interesting assumption - then cases of the sort discussed before would not constitute any counter-example to claim (T). In effect, an instantiation of the principle to Jones's case would turn out to be (again) trivially true since its antecedent would turn out to be false; for the second conjunct in the antecedent of $(\mathbf{T})$ would not hold:

17. On the transparency of sense in general, see John Campbell, “Is Sense Transparent?", Proceedings of the Aristotelian Society 88 (1987/88), 273-92.

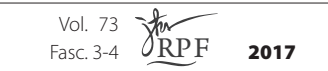


it is not the case that Jones disbelieves at 00:01 a.m. on $\mathbf{d + 1}$ a thought to the effect that the preceding day was fine. Moreover, the envisaged version of the Transparency principle - strengthened in a certain way, viz. as in (T)* below - might even be argued to be in general (trivially) true from a Fregean viewpoint. Thus, consider the following claim:

$(T) *$ If a rational subject $x$ believes that $p$ at $t$ and disbelieves that $q$ at $t^{\prime}$ and the thought that $p=$ the thought that $q$ and $x$ retains his belief that $p$ from $t$ to $t^{\prime}$, then $x$ knows at $t^{\prime}$ that the thought that $p=$ the thought that $q$ (with $t^{\prime}$ different from $t$ ).

One might argue that the antecedent of $\mathbf{( T ) *}$ does not hold in general on the basis that it would be inconsistent with a certain diachronic generalization of the Intuitive Criterion of Difference for thoughts. I have tried elsewhere ${ }^{18}$ to put forward what I take to be a plausible formulation of such an extended principle; and if my attempt is successful then (T)* should be seen as a trivial truth. (It is interesting to notice that (T), as well as $(\mathbf{T})^{*}$, would presumably hold under a Millian account of thoughts and attitude-attributions).

Of course, it does not follow that the neo-Fregean theorist should be seen as subscribing in general to the idea that thoughts are transparent to their thinkers. On the contrary, there are several senses in which Fregean thoughts are opaque to their thinkers. Indeed, there are several versions of the Transparency principle that would be regarded as false under a neo-Fregean account of indexicality. Thus, take the following sort of claim:

(I) If $x$ entertains at $t$ the thought that $p$ and $x$ entertains at $t^{\prime}$ the thought that $q$ and the thought that $p$ is different from the thought that $q$, then $x$ knows at $t^{\prime}$ that the thought that $p$ is different from the thought that $q$.

This claim would be unacceptable in the light of neo-Fregeanism. Suppose that at $\mathbf{t}$ Ralph, looking at a certain object o, judges 'That is nice'. Meanwhile someone replaces $\mathbf{o}$ with a distinct (but rather similar) object o' without Ralph noticing it. Later on, at $\mathbf{t}^{\prime}$, looking at what is in fact

18. João Branquinho, "On the Individuation of Fregean Propositions". in Analytic Philosophy and Logic. The Proceedings of the 20th World Congress of Philosophy, Vol. VI, ed. A. Kanamori (Bowling Green, Ohio: Philosophy Documentation Center, 2000), $17-28$.

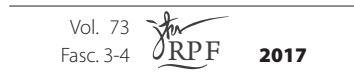


o', Ralph comes to wonder whether the object perceptually presented to him is nice. Assume that Ralph is a self-reflective Fregean thinker who is agnostic at $\mathbf{t}^{\prime}$ about whether the thought he is then entertaining is the same as the thought he entertained at $\mathbf{t}$. Such thoughts are surely different from one another for they are about distinct objects. But, since the thinker is unsure whether he has successfully tracked the object thought about at $\mathbf{t}$ from $\mathbf{t}$ to $\mathbf{t}^{\prime}$, he cannot be in a position to know at t' that the thoughts in question are different.

It is interesting to ascertain whether the following variant of claim (I) would be consistent with neo-Fregeanism (it would presumably be consistent with Millianism):

\section{(I)* If $\mathrm{x}$ entertains at $\mathrm{t}$ the thought that $\mathrm{p}$ and $\mathrm{x}$ entertains at $\mathrm{t}^{\prime}$ the thought that $q$ and the thought that $p=$ the thought that $q$, then $x$ knows at $t$ ' that the thought that $p=$ the thought that $q$.}

Suppose that Ralph's case is described as before except that this time nobody replaces o between $\mathbf{t}$ and $\mathbf{t}^{\prime}$, while Ralph thinks that a switch has taken place. Yet, he comes to judge at t' 'That is nice'. Thus, he wrongly thinks at $\mathbf{t}^{\prime}$ that he is then entertaining a distinct thought.

This sort of cases seem to provide us with prima facie straightforward counter-examples to claim (I)*. Indeed, if the subject thinks that the thoughts he entertains on different occasions are distinct, and if such thoughts are in fact one and the same, then it follows that it will not be the case that he knows that they are identical. The problem is that, on the neo-Fregean view, the second premise of such an inference cannot be taken for granted (with respect to cases like the one above). In effect, perceptual singular modes of presentation are supposed to be based on abilities to keep track of objects over time and/or space, as well as from sensory modality to sensory modality. Hence, it is at least arguable that the Fregean thoughts entertained by Ralph at $\mathbf{t}$ and $\mathbf{t}$ ' are not to be counted as being identical; indeed, one might claim that it would not make much sense to say, with respect to the above sort of circumstances, that Ralph has in fact tracked the object $\mathbf{o}$ from $\mathbf{t}$ to $\mathbf{t}^{\prime}$. It sounds in a sense weird to say that someone has unknowingly kept track of an object, though it surely makes sense to say that someone has unknowingly mistracked an object. Thus, one might reason as follows with a view to showing that claim (I)* is, in general, not inconsistent with the brand of neo-Fregeanism under consideration. Restricting our attention to indexical thoughts of the envisaged types, it seems that on such a view the only way in which particular thoughts $\mathbf{p}$

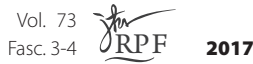


and $\mathbf{q}$ - both about a given object $\mathbf{o}$ - could be taken as identical is that the thinker who entertains them (on different occasions and/or at different places, etc.) keeps track of $\mathbf{o}$. But if the above suggestion is correct then, in general, it does not make sense to say of a thinker that he unknowingly has kept track of an object. Therefore, the thinker could not be in a position to think that $\mathbf{p}$ and $\mathbf{q}$ are distinct thoughts; and hence the conclusion would apparently be blocked that she does not know that $\mathbf{p}$ and $\mathbf{q}$ are one and the same thought. Having our present concerns in mind, I shall not try to assess such an argument and settle the issue here; I prefer to leave it open. But one might at least conclude that, on the neo-Fregean account, a claim such as (I)* cannot be conclusively shown to be false on the basis of the sort of cases discussed.

\section{References}

Branquinho, João. "On the Individuation of Fregean Propositions". In Analytic Philosophy and Logic. The Proceedings of the 20th World Congress of Philosophy, Vol. VI, edited by A. Kanamori, 17-28. Bowling Green, Ohio: Philosophy Documentation Center, 2000.

Branquinho, João. “Are Salmon's ‘Guises’ Disguised Fregean Senses”. Analysis 50 (1990): 19-24.

Branquinho, João. 'On the persistence and re-expression of indexical belief. Manuscrito 31, no. 2 (2008): 573-600.

Campbell, John. “Is Sense Transparent?”. Proceedings of the Aristotelian Society 88 (1987/88): 273-92.

Evans, Gareth. "Understanding Demonstratives”. In Meaning and Understanding, edited by Herman Parret and Jacques. Bouveresse. Berlin: W. de Gruyter, 1981. Reprinted in Gareth Evans, Collected Papers, 291-321. Oxford: Clarendon Press. 1985.

Evans, Gareth. The Varieties of Reference, edited by John McDowell. Oxford: Clarendon Press and New York: Oxford University Press. 1982.

Forbes, Graeme. "Indexicals and Intensionality: A Fregean Perspective". The Philosophical Review 96, no. 1 (1987): 3-31.

Forbes, Graeme. "Indexicals". In Handbook of Philosophical Logic, Volume IV, edited by D.Gabbay and F.Guenthner, 463-90. Dordrecht: David Reidel, 1989.

Frege, Gottlob. "The Thought: A Logical Inquiry". Translated by Anthony and Marcelle Quinton. In Philosophical Logic, edited by Peter F. Strawson, 17-38. Oxford: Oxford University Press, 1967.

McDowell, John. “De Re senses”. The Philosophical Quarterly 34, no. 136 (1974): 98-109.

McGinn, Colin. The Subjective View. Oxford: Clarendon Press, 1983.

Mertel, Kurt C.M. "Re-Thinking Gareth Evans' Approach to Indexical Sense and the Problem of Tracking Thoughts". Grazer Philosophische Studien 94, Issue 1-2 (2017): 173-193. DOI: 10.1163/18756735-000013

Peacocke, Christopher A.B. Sense and Content. Experience, Thought and their Relations. Oxford: Clarendon Press, 1983.

Peacocke, Christopher A.B. Thoughts: An Essay on Content. Oxford: Basil Blackwell, 1986.

Récanati, François. Mental Files in Flux. Oxford: Oxford University Press, 2016.

Salmon, Nathan. Frege's Puzzle. Cambridge, Mass. and London, England: The MIT Press, 1986.

Salmon, Nathan. "Illogical Belief". In Philosophical Perspectives, Vol. 3: Philosophy of Mind and Action Theory. Edited by James E.Tomberlin, 243-285. Atascadero: Ridgeview, 1989.

Salmon, Nathan. "A Millian heir rejects the wages of Sinn". In Propositional Attitudes: the Role of Content in Logic, Language and Mind, edited by C.A. Anderson and J. Owens, 215-48. Stanford: CSLI, 1990.

Schiffer, S. "The Mode-of-Presentation Problem". In Propositional Attitudes: The Role of Content in Logic,

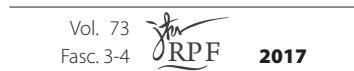

Provided for Personal License use. Not for reproduction, distribution, or commercial use.

(c) 2017 Revista Portuguesa de Filosofia. All Rights Reserved. 
Language and Mind, edited by C.A. Anderson and J. Owens, 249-68. Stanford: CSLI, 1990.

Searle, John. Intentionality: An Essay in the Philosophy of Mind. Cambridge: Cambridge University Press, 1983.

Soames, Scott. "Direct Reference, Propositional Attitudes, and Semantic Content". Philosophical Topics 15 (1987): 47-87. Reprinted in Propositions and Attitudes, edited by Nathan Salmon and Scott Soames, 197-239. Oxford: Oxford University Press, 1988.

Soames, Scott. "Substitutivity”. In On Being and Saying: Essays for Richard Cartwright, edited by J.J. Thomson, 99-132. Cambridge: Cambridge University Press, 1988.

Soames, Scott. "Review of Gareth Evans, Collected Papers". The Journal of Philosophy 86 (1989): 141-56.

Provided for Personal License use. Not for reproduction, distribution, or commercial use. (C) 2017 Revista Portuguesa de Filosofia. All Rights Reserved. 